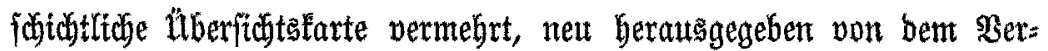

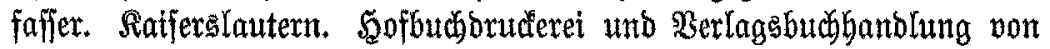
Sermann Raijer. 1895. Prets 1 \%.

Wie jodpn ber Iitel bejagt, exifiten bie vorliegenbe verbientituolle tmo milhevolle Stubie bereits im Jahrgang 1895 biejer $\mathfrak{B l a ̈ t t e r . ~ J a d ~}=$

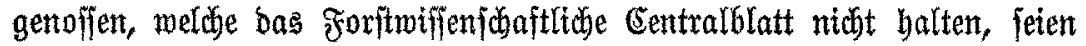
Daber auf biefe neue litt. Endhetnung aufmertian gemadht. Dâs bie

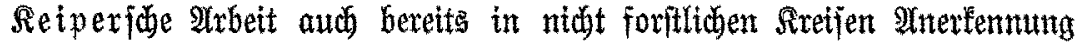
gefunden bat, folgt fofon baraus, bajs bie erfte 2uflage auf Soften ber

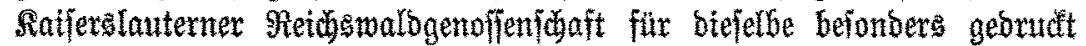
wurbe.

\title{
IV. Alotizen.
}

\section{Entebertht itber $\mathfrak{W}$ aldjanter.}

Bon Seitrith seffer Soht Darmftat. Mabelgolziamen.

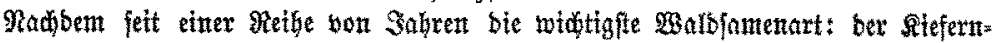

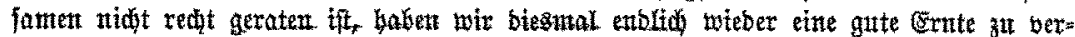
zetdnen. Da auth beim Zapfettentouf biesmal wentger pretstreiberei unter ben fonfurrierenben alenganfolten als frither berridgte, founten bte Bapfen zu fegr mäpigent Preife ctagefint werben.

Der \$reis bes Riefernfomens ift infolgebeffen it biejen Sabre fo billig, wie er

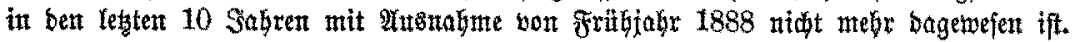

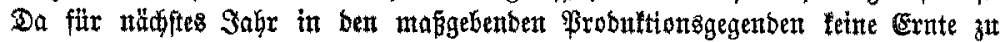
exwarten ift, empfeble id bringenb

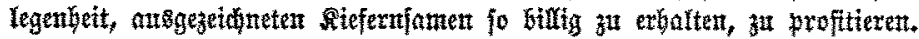

Setne anbere Rabelholgart hat eine gleid ginftige Santentrute anfzutueffert.

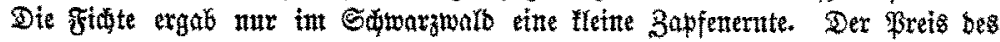

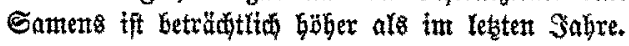

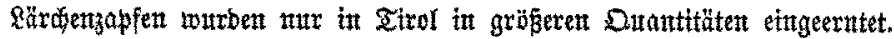

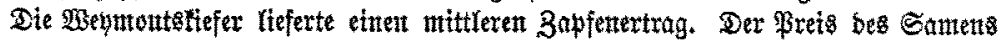
ift ein mäşiger.

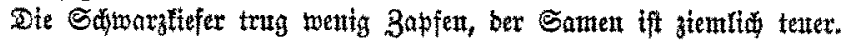

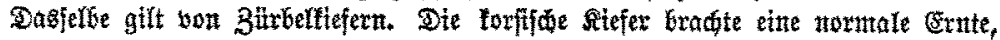

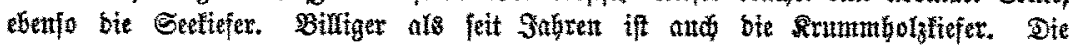
Weištantue gab entent reidfiden Samenertrog von gnter Dnalität.

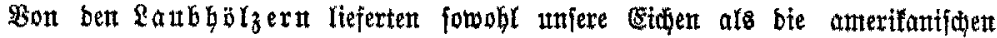

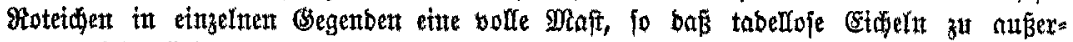
gewointitid mäfigen Bretie geftefert werben lonten.

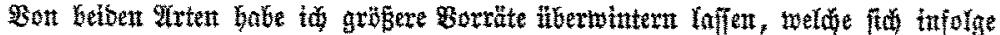

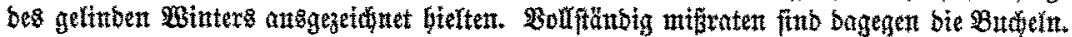

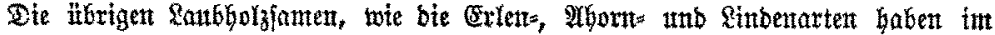
allgemeinet mittlere Samen = Extne ergethen.

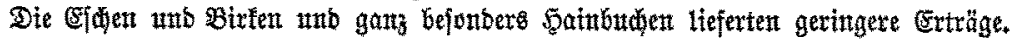

